\title{
Influences of Korean Elementary Schoolers' Playfulness on Leisure Lifestyles
}

\author{
Hyoung-Kil Kang ${ }^{1}$, Sunhwan Hwang ${ }^{2}$ \\ ${ }^{1}$ Kyungnam University, South Korea \\ ${ }^{2}$ University of Seoul, South Korea
}

\begin{abstract}
.
The purpose of this study is to elucidate the relationship between Korean elementary schoolers' playfulness and leisure lifestyles. Questionnaires were administered to 300 Korean elementary school students in five elementary schools, and 278 collected questionnaires were used for data analysis. Exploratory factor analysis, correlation analysis, and multiple regression analysis were conducted using SPSS 18.0. Multiple regression analyses showed that emotional fluidity playfulness positively influenced reasonable plan, sensory pursue, and relationship centered leisure lifestyles and negatively influenced indifferent leisure lifestyles. Physical animation playfulness positively influenced reasonable plan, sensory pursue, and relationship centered leisure lifestyles. Humorous perspective playfulness positively influenced workcentered leisure lifestyles. Mental spontaneity playfulness positively influenced relationship centered leisure lifestyles. The findings indicated that playfulness is an important predictor of leisure lifestyles. In discussion section, theoretical and practical implications are provided.
\end{abstract}

Keywords: playfulness, leisure lifestyles, Korean elementary schoolers, happiness 


\section{Introduction}

Playfulness can provide developmental benefits for children, and psychology studies have focused on children's playfulness. However, in the leisure literature, a paucity of research regarding children's playfulness and leisure lifestyles is found, and this study aims to elucidate the relationship between Korean elementary schoolers' playfulness and leisure lifestyles. What follows is a brief literature review of why this study selects Korean elementary schoolers for this study participants and why to choose playfulness and leisure lifestyles as an independent and a dependent variable of this study respectively.

Happiness can be the purpose of life, and in particular, the happiness of elementary schoolers is important because elementary schoolers' happiness directly affects various psychological and behavioural factors. For example, adolescents with low happiness are likely to be exposed to school violence, flight behaviour, and game addiction, and is more likely to be depressed. More importantly, elementary schoolers with low happiness are likely to experience low happiness throughout their life cycle (Entwisle \& Hayduk, 1988). Despite of the importance of children's happiness, the level of the happiness of Korean elementary schoolers is the lowest in international comparison, and more than $50 \%$ of Korean elementary schoolers report that they are unhappy (Kim \& Lee, 2009). In addition, from 2009 to 2016, the well-being index of Korean children and adolescents has been remained at the lowest level among OECD countries. Considering this, Korean elementary schoolers' happiness needs to be improved. This study poses that active leisure lifestyles can be a way to improve Korean elementary schooler' happiness because active leisure lifestyles directly improve happiness (Kang \& Choi, 2015). By making more Korean elementary schoolers choose active leisure lifestyles, the levels of happiness of Korean elementary schoolers can be increased. Thus this study selects Korean elementary schoolers as study participants and choose leisure lifestyles as variables that can improve happiness of Korean elementary school students.

By using leisure lifestyle, we can understand people's specific and continuous behaviors and psychological tendencies in leisure contexts (Mannel \& Kleiber, 1997). Woo and Sohn (2009) proposed that the Korean leisure lifestyle consists of seven domains including reasonable plan leisure lifestyle, relationship-centered leisure lifestyle, indifferent leisure lifestyle, sensory pursue leisure lifestyle, work-centered leisure lifestyle, accessibility-centered leisure lifestyle, and family-centered leisure lifestyle. People with reasonable plan leisure lifestyle like to search the best possible leisure activity and plan leisure activity in detail. People with relationship-centered leisure lifestyle are concerned less about the type of leisure activity but more concerned about those with whom they participate in leisure activity. They often use leisure activity as a tool for their social relationships. Indifferent leisure lifestyle people often have no plan and no interest for their leisure activity. People with sensory pursue leisure lifestyle want to have thrilled and unique leisure activity such as cliff diving and $\mathrm{X}$ sport. Workcentered leisure lifestyle people despise the value of leisure in their life, and even when they are participating in their leisure activity, they keep thinking about their works. Accessibilitycentered leisure lifestyle people think that the accessibility of leisure activity is the most important factor to choose an activity for their leisure time, so watching TV is often found to be their choice of leisure activity. Family-centered leisure lifestyle is a similar lifestyle with relationship-centered leisure lifestyle, but instead of colleagues or friends, spending time with family members is a key factor when they decide an activity for their leisure time. This study proposes that these five leisure lifestyles can be influenced by their playfulness. 


\section{SOCIAL SCIENCES IN THE 21ST CENTURY}

Many people regard play as pleasure-pursued non-purposive activity. However, play is more than activity. Play is a way of thinking of activities, and people has to have the desire to play and must internally perceive an activity as play to truly play (Rubin, Fein, \& Vandenberg, 1983; Liebermann, 1977). Studies reported five subfactors of playfulness including social engagement, mental spontaneity, humorous perspectives, physical animation, and emotional fluidity (Barnett \& Kleiber, 1982; Staempfli, 2005). Kim, Kim, and Park (2012) described the five types of playfulness as follows. First People with high social engagement playfulness like interactions with others and deeply concerned with whom they play with. Second, mental spontaneity is closely associated with imagination, and people with strong mental spontaneity playfulness enjoy to play role games and like to imagine themselves in being different kinds of people. Third, people with high humorous perspective playfulness like to hear funny story and jokes and tend to tell people funny story. Fourth, physical animation playfulness is strongly correlated with physicality, and people with strong physical animation playfulness enjoy physical activity. Lastly, people with high emotional fluidity playfulness often and freely exhibit their enjoyment, passion, and pleasure when they play.

Through these five components of playfulness, we can understand characteristics of children and predict children's behavioral and psychological tendencies. For example, high playfulness children are more creative and have better communication skills than those with low playfulness (Jenkinson, 2001; Meador, 1992). In addition, children with more playfulness possess better skills of discovering new solutions and more capable of dealing with frustration and anxiety than those with less playfulness (Moran, 1987). Importantly, playfulness has life-long effects on happiness and well-being (Proyer, 2014). As such, playfulness can influence a variety of behaviors and psychological traits of children. However, little research has investigated how elementary schoolers' playfulness affects leisure lifestyles. Thus this study attempts to investigate how playfulness influences leisure lifestyles.

\section{Methods}

Questionnaires were distributed to a total of 300 students in five elementary schools in I city, and 278 questionnaires were used for data analysis after the exclusion of 22 incomplete questionnaires. To measure playfulness, this study used 20 items developed by Staempfli (2005). Playfulness items were translated into Korean by three leisure scholars who completed their Ph. D. in the United States. To measure leisure lifestyles, 21 items developed by Choi, Choi, and Lee (2014) were used. Exploratory factor analyses using principal component analysis and Varimax rotation were conducted. To factorize the items, Eigen value above one and factor loadings higher than .5 were used. In addition, Kaiser-Meyer-Olkin value and Bartlett's test of sphericity were accessed to determine the acceptability of exploratory factor analysis. Cronbach's alpha was used to access internal consistency of subsets (Kline, 2000). After exploratory factor analyses, four subfactors of playfulness and five subfactors of leisure lifestyles were factorized in this study sample. With the factorized subfactors, correlation analysis and multiple regression analysis were conducted to identify the relationship between playfulness and leisure lifestyles.

\section{Results}

Correlation analysis showed that most subsets of variables were significantly positively correlated except for indifferent leisure lifestyles and work-centred leisure lifestyles. The 


\section{SOCIAL SCIENCES IN THE 21ST CENTURY}

highest correlation value is .536 , so there is no muticollinearity issue found in the variables (Berry, 1993). The summary of the correlation analysis of this study variables is presented in Table 1.

Table 1. Correlations of variables

\begin{tabular}{lccccccccc} 
& $(1)$ & $(2)$ & $(3)$ & $(4)$ & $(5)$ & $(6)$ & $(7)$ & $(8)$ & $(9)$ \\
\hline \hline (1) Humorous Perspective & 1 & $.536^{* *}$ & $.427^{* *}$ & $.504^{* *}$ & $.366^{* *}$ & $.334^{* *}$ & -.022 & $.297^{* *}$ & $.209^{* *}$ \\
(2) Emotional Fluidity & 1 & $.454^{* *}$ & $.506^{* *}$ & $.438^{* *}$ & $.426^{* *}$ & $-.181^{* *}$ & $.409^{* *}$ & .089 \\
(3) Physical Animation & & 1 & $.390^{* *}$ & $.361^{* *}$ & $.403^{* *}$ & .017 & $.401^{* *}$ & .048 \\
(4) Mental Spontaneity & & & 1 & $.359^{* *}$ & $.342^{* *}$ & -.012 & $.371^{* *}$ & .086 \\
(5) ReasonablePlan & & & & 1 & $.410^{* *}$ & -.099 & $.463^{* *}$ & .099 \\
(6) Sensory pursue & & & & & 1 & -.046 & $.376^{* *}$ & .003 \\
(7) Indifferent & & & & & & 1 & -.082 & $.139^{*}$ \\
(8) Relationshipcentered & & & & & & & 1 & .113 \\
(9) Workcentered & & & & & & & & 1 \\
\hline
\end{tabular}

${ }^{*} \mathrm{p}<05, *{ }^{*} \mathrm{p}<.01, * * * \mathrm{p}<.001$

Multiple regression analyses showed that emotional fluidity playfulness positively influenced reasonable plan, sensory pursue, and relationship centered leisure lifestyles and negatively influenced indifferent leisure lifestyles. Physical animation playfulness positively influenced reasonable plan, sensory pursue, and relationship centered leisure lifestyles. Humorous perspective playfulness positively influenced work-centered leisure lifestyles. Mental spontaneity playfulness positively influenced relationship centered leisure lifestyles.

Merely considering the mean scores of subsets of playfulness and leisure lifestyles, Korean elementary schoolers have subsets of leisure lifestyles in the order, relationship centered leisure lifestyle, sensory pursue leisure lifestyle, reasonable plan leisure lifestyle, work-centered leisure lifestyle, and indifferent leisure lifestyle. Korean elementary schoolers have subsets of playfulness in the order, emotion fluidity, mental spontaneity, physical animation, and humorous perspectives playfulness. The summary of the multiple regression analysis of playfulness and leisure lifestyles is presented in Table 2.

Table 2. Multiple regression analysis of playfulness and leisure lifestyles

\begin{tabular}{cccccc}
\hline $\begin{array}{c}\text { Dependent } \\
\text { Variables }\end{array}$ & Independent Variables & $\beta$ & $t$ & $F$ & $R^{2}$ \\
\hline \hline & Humor $(M=3.11, S D=.99)$ & .110 & 1.588 & & \\
Reasonable Plan & Emotion $(M=3.75, S D=.84)$ & .249 & $3.524 * *$ & & \\
$(M=3.28, S D=.91)$ & Physical $(M=3.46 S D=1.02)$ & .159 & $2.501 *$ & & \\
& Spontaneity $(M=3.49, S D=.89)$ & .104 & 1.556 & & \\
\cline { 1 - 3 } Sensorypursue & Humor $(M=3.11, S D=.99)$ & .057 & .815 & \multirow{2}{*}{$19.882^{* * * *}$} & .238 \\
$(M=3.33, S D=.99)$ & Emotion $(M=3.75, S D=.84)$ & $.243 * *$ & $3.438^{* *}$ & & \\
\hline
\end{tabular}




\begin{tabular}{|c|c|c|c|c|c|}
\hline & $\begin{array}{c}\text { Physical }(M=3.46 S D=1.02) \\
\text { Spontaneity }(M=3.49, S D=.89)\end{array}$ & $\begin{array}{c}.223 * * \\
.092\end{array}$ & $\begin{array}{c}3.513 * * \\
1.362 \\
\end{array}$ & & \\
\hline \multirow{4}{*}{$\begin{array}{c}\text { Indifferent } \\
(M=2.08, S D=.89)\end{array}$} & Humor $(M=3.11, S D=.99)$ & .045 & .575 & \multirow{4}{*}{$2.892^{*}$} & \multirow{4}{*}{.044} \\
\hline & Emotion $(M=3.75, S D=.84)$ & -.264 & $-3.358^{*}$ & & \\
\hline & $\operatorname{Physical}(M=3.46 S D=1.02)$ & .059 & .819 & & \\
\hline & Spontaneity $(M=3.49, S D=.89)$ & .082 & 1.085 & & \\
\hline \multirow{4}{*}{$\begin{array}{l}\text { Relationship centered } \\
(M=3.63, S D=.88)\end{array}$} & Humor $(M=3.11, S D=.99)$ & -.005 & -.072 & \multirow{4}{*}{$20.21 * * *$} & \multirow{4}{*}{.242} \\
\hline & Emotion $(M=3.75, S D=.84)$ & .215 & $3.059 * *$ & & \\
\hline & $\operatorname{Physical}(M=3.46 S D=1.02)$ & .227 & $3.573 * * *$ & & \\
\hline & Spontaneity $(M=3.49, S D=.89)$ & .181 & $2.702 * *$ & & \\
\hline \multirow{4}{*}{$\begin{array}{c}\text { Work centered } \\
(M=3.03, S D=1.12)\end{array}$} & Humor $(M=3.11, S D=.99)$ & .242 & $3.14 * *$ & \multirow{4}{*}{$3.49 * *$} & \multirow{4}{*}{.052} \\
\hline & Emotion $(M=3.75, S D=.84)$ & .005 & .066 & & \\
\hline & $\operatorname{Physical}(M=3.46 S D=1.02)$ & -.046 & -.650 & & \\
\hline & Spontaneity $(M=3.49, S D=.89)$ & -.003 & -.039 & & \\
\hline
\end{tabular}

${ }^{*} \mathrm{p}<.05$, ** $\mathrm{p}<.01$, ***p<.001, Physical Animation(Physical), Humorous Perspective(Humor), Emotional Fuidity(Emotion), Mental Spontaneity(Spontaneity).

\section{Discussion}

Well-being and the perception of quality of life are positively associated with the positive leisure lifestyle (Kang, 2010). The positive leisure lifestyle also leads individuals to reach selffulfilment and their full potential (Stebbins, 2005). Recently Kang and Cho (2018) posed that reasonable plan, sensory pursue, and relationship centered leisure lifestyles can be considered positive leisure lifestyles and indifferent and work-centered leisure lifestyles can be regarded as negative leisure lifestyles. With playfulness, this study attempted to explore a possible way to reach positive leisure lifestyle.

Multiple regression analysis showed that emotional fluidity positively influenced reasonable plan, sensory pursue, and relationship centered leisure lifestyles, all of which are categorized by positive leisure lifestyles and negatively influenced indifferent leisure lifestyles, one of negative leisure lifestyles (Kang \& Cho, 2018). Findings suggested that Korean elementary schoolers need to develop their emotional fluidity playfulness with which they more likely pursue positive leisure lifestyles and less likely choose negative leisure lifestyles. High emotional fluidity playfulness is associated with willingness of exhibiting enjoyment, passion, and pleasure (Kim, Kim, \& Park, 2012). In Korean culture, it is a virtue to endure to reveal emotions, and children are taught to not show their emotion to others. This study findings suggested that this tradition needs to be changed, and parents having elementary schoolers and elementary school teachers encourage their children and students to show their positive emotion. In the same line, physical animation playfulness can increases likelihood for elementary schoolers to have positive leisure lifestyles. Physical activity can be a way to improve physical animation playfulness. A number of studies have shown that physical activity provided psychological and physiological benefits for children. This study added an empirical evidence that children need to actively participate in physical activity. 


\section{SOCIAL SCIENCES IN THE 21ST CENTURY}

\section{Conclusion}

The purpose of this study is to elucidate the relationship between Korean elementary schoolers' playfulness and leisure lifestyles. This study found that playfulness is a predictor of leisure lifestyle, and nuturing emotion fluidity and physical animation playfulness is important for elementary school students to have positive leisure lifestyles. Given that positive leisure lifestyles contribute to happiness, researchers need to consider playfulness a means to find solutions to the internatioanlly lowest happiness of Korean elementary schoolers. Some may consider that elementary schoolers' playfulness causes disruptive behaviors at home and in classrooms and even describe playfulness in negative ways (Leipold \& Bundy, 2000). But this study found that playfulness certainly has positive influences on positive leisure lifestyles and proposed that more future research endeavors needs to be directed to playfulness' role in leisure. 


\section{References}

Barnett, L., \& Kleiber, D. (1982). Concomitants of playfulness in early childhood: Cognitive abilities and gender. The Journal of Genetic Psychology, 141,115-127.

Berry, W. D. (1993). Understanding regression assumptions. Sage university paper series on quantitative applications in the social sciences, Newbury Park, CA: Sage.

Choi, B. A., Choi, J. I., \& Lee, J. W. (2014). Validation of leisure lifestyle scale in golf player using Rasch model. The Korean Journal of Sports Science, 23(1), 61-75.

Entwise, D. R., \& Hayduk, L. A. (1988). Lasting effects of elementary school. Sociology of Education. Sociology of Education, 61(3), 147-159.

Jenkinson, S. (2001). The genius of play. Glocestershire, UK: Hawthorne Press.

Kang, H. K. (2010). Exploring how dimensions of leisure time physical activity relate to quality of life perception. Unpublished dissertation, University of Minnesota, Twin-Cities.

Kang, H. K., \& Cho, H. T. (2018). The impacts of basic psychological needs satisfaction in physical education class on positve leisrue lifestyle: A case of female high school students. Korean Journal of Leisrue, Recreation \& Park, 42(2), 53-64.

Kang, H. K., \& Choi, M. H. (2015) Youths' levels of leisure time physical activity, enjoyment, time perspectives, and subjective well-being, Korean Journal of Recreation, Parks, and Leisure Studies, 39(4), 56-70.

Kim, A. Y., \& Lee, M. Lee. (2008). Structural relationships among adolescents' psychological need satisfaction, depressive tendency, and school adjustment in middle- and high school. The Korean Journal of Education Psychology, 22(2), 423-441.

Kim, M. S., Kim, G. S., \& Park, C. H. (2012). The development and validity of the children's playfulness rating scale. Korean Journal of Child Studies, 33(2), 69-89.

Kline, R. B. (2005). Principles and practice of structural equation modeling (2nd ed.). New York: Guilford Press.

Leipold, E., \& Bundy, A. (2000). Playfulness in children with attention deficit hyperactivity disorder. The Occupational Therapy Journal of Research, 20(1), 61-82.

Liebermann, J. N. (1977). Playfulness: its relationship to imagination and creativity. New York: Academic Press.

Mannell, R., \& Kleiber, D. (1997). A social psychology of leisure. State College, PA: Venture Publishing, Inc.

Meador, K.S. (1992). Emerging rainbows: A review of the literature on creativity in preschoolers. Journal for the education of the gifted, 15, 163-181.

Moran, G.S. (1987). Some functions of play and playfulness: A developmental perspective. Psychoanalytic Study of the Child, 42, 11-29.

Proyer, R. T. (2014). Playfulness over the lifespan and its relation to happiness: Results from an online survey. Z Gerontol Geriat, 47, 508-512.

Rubin, K. H., Fein, G., \& Vanderberg, B. (1983). Play. (Vol. IV-Socialization, Personality, and Social Development). New York: Wiley. 
Staempfli, M. B. (2005). Adolescent playfulness, leisure, and well-being, unpublished dissertation, University of Waterloo.

Woo, S. N. \& Sohn, Y. M. (2009). The development study of the leisure life style scale. Journal of Leisure Studies, 7(1), 1-26. 